\title{
The Role of Libraries in American Indian Tribal College Development
} Cheryl Duran

\begin{abstract}
This paper presents a model for assessing the role libraries play in meeting the institutional goals and objectives of the American Indian tribal colleges. The Carnegie Report entitled Tribal Colleges: Shaping the Future of Native America serves as the departure point for this assessment. In analyzing the library's role, the paper applies to tribal colleges an organizational development model constructed by Eric G. Flamholtz. The model identifies key developmental tasks associated with four stages of organizational growth: (1) new venture; (2) expansion; (3) professionalizing; and (4) consolidation. The analysis considers parallels between the tribal colleges' tasks and the libraries' tasks. Application of the development model suggests a set of hypotheses that frame the role of the library in meeting the institutional goals and objectives of the colleges. The library-related hypotheses consider the three unique tribal college goals: (1) preserving tribal culture; (2) enhancing community economic opportunity; and (3) improving health care. The next phase of this investigation will consist of extensive data gathering from the twenty-four tribal colleges to test the hypotheses identified in this paper and to generate additional hypotheses and research in the area of tribal college libraries.
\end{abstract}

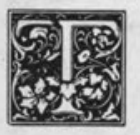

his study assesses the role of the library in meeting the goals and institutional objectives of American Indian tribal colleges. There has been nominal discussion of the status of tribal colleges in the general higher education literature and virtually no discussion of tribal college libraries in the library and information science literature. I will present an overview of tribal colleges, identify their objectives, and then consider the fulfillment of these objectives by applying an organizational development model to the tribal colleges. Finally, from this model I will derive a set of hypotheses that consider the contribution of library and information resources to meeting these institutional objectives.
Based on the hypotheses formulated in this paper, future research will include an extensive longitudinal study on the role of libraries in tribal college development. A focus group drawn from the tribal college presidents perceives these hypotheses as relevant.

\section{THE DEVELOPMENT OF THE TRIBAL COLLEGE}

The development of American Indian tribal colleges represents the determination of native peoples to achieve academic excellence rooted in cultural traditions. Tribal colleges seek to rectify the inability of the U.S. government to honor the educational provisions agreed upon in more than 300 treaties dating from $1778 .^{1}$ of California, Los Angeles, California 90024. 
Federal control of Indian education, excluding mission schools, began in 1870 with a $\$ 100,000$ appropriation to operate federal industrial schools. ${ }^{2}$ One of the few successful efforts in higher education was the 1882 founding of the Haskell Indian School (in 1965 renamed Haskell Junior College) in Lawrence, Kansas. In 1887, the Lumbees established Old Main Indian College at Pembroke, North Carolina. ${ }^{3 / 4}$ In the early twentieth century, the idea of an American Indian college was proposed by a number of American Indians, including August Breuninger (Menominee), who in 1911 suggested the development of an Indian university. Arthur C. Parker (Seneca) established the Society of American Indians to found an "Indian College." 5

It was not until the 1960 s that American Indian higher education became of pivotal concern to both American Indian communities and the federal government. Beginning in 1965 and extending into the 1970s, American Indians lobbied for the passage of legislation to support the establishment of tribally controlled higher education in their communities. The thrust of this predominantly federal legislation was to enable American Indians to affect the direction and expansion of American Indian education. Consequently, the educational system changed from one that had been controlled by religious and governmental agencies to one designed and controlled by American Indian communities. Thus, the task became to manage major change in American Indian higher education. A primary manifestation of this change was the development of tribally controlled colleges. These colleges have been confronted not only with meeting the challenges faced by all traditional community colleges, but also with the need to ensure that their institutional objectives coincide with their cultural imperatives. ${ }^{6}$

\section{TRIBAL COLLEGE OBJECTIVES}

The objectives of tribal colleges are not significantly different than those of other community colleges. Arthur Cohen identified five educational objectives that com- munity colleges in America attempt to meet:

1. Preparation for transfer, typically to four-year colleges;

2. Preparation for job entry, both professional and paraprofessional;

3. Literacy development;

4. Career upgrading and skill enhancement; and

5. Support of personal interest activities.?

In addition to establishing curricula and practices to achieve these five objectives, tribal colleges also have defined a set of goals that are intrinsic to their mission: (1) preserving and communicating traditional culture; (2) enhancing economic opportunity within the reservation community; and (3) improving health care at the community level through support or participation in alcohol and drug abuse programs. ${ }^{8}$

While adequate funding is a standard concern of all community colleges, it is even more critical and complex for tribal community colleges.

These three goals were identified in a recent Carnegie Special Report, Tribal Colleges: Shaping the Future of Native America, as meriting immediate action and additional research. The Carnegie Report cited two reasons, also supported by the tribal college presidents, for emphasizing these goals. The primary rationale is to provide an educational curriculum that can help rectify the negligence of the federal government's policies and practices regarding American Indian higher education. The second reason is to define explicitly the role of the tribal college in facilitating community development and promoting economic self-determination. The Carnegie Report offered a set of recommendations aimed at enabling tribal colleges to manage better their growth and to shape their own educational future. (As previously noted, the fundamental change was movement from nonindigenous control of education to indigenous de- 
sign and management of education.) The Carnegie Report also identified assessment criteria for evaluating tribal colleges' ability to meet their objectives. These criteria depend on adequate funding, staffing, and accreditation.

While adequate funding is a standard concern of all community colleges, it is even more critical and complex for tribal community colleges. The funding issue is complex in that it involves analysis and application of treaties, federal legislation, state and local laws, private sources, and tribal allocations. Inadequate funding affects the stability of faculty and administration. The Carnegie Report and other studies have identified low pay, large teaching loads, and geographic isolation as the funding issues that contribute to substantial faculty and administration turnover. ${ }^{9}$ The Carnegie Report suggested that these high rates of turnover have had an adverse effect on the colleges' ability to meet accreditation standards, support existing academic programs, and maintain linkages with the student body and community as a whole.

Historically, the primary indicator of institutional performance and recognition has been the achievement of accreditation. For community colleges, including tribal community colleges, institutional accreditation means that "a postsecondary institution's own goals are soundly conceived, that its educational programs have been intelligently devised, that its purposes are being accomplished, and that the institution is so organized, staffed, and supported that it should continue to merit confidence."10 Navajo Community College, the first tribally controlled college, was chartered in 1968 at Tsaile, Arizona, as a result of the interest and determination of the Navajos. At present there are twenty-six tribally controlled colleges in the United States and two in Canada. Twenty-four of the twenty-six tribally controlled colleges are tribally chartered institutions. They are located primarily in the Northwest, with seven in Montana, five in North Dakota, and four in South Dakota. " Twelve of these are accredited and eight are candidates for accreditation. ${ }^{12}$ Given the relatively short history of American Indian tribal colleges, the results have been remarkable. The ability to acquire adequate funding, retain faculty and administrators, and achieve accreditation are all measures of institutional performance. Before considering the role of libraries in the assessment of institutional performance, it is necessary to provide a brief description of the colleges' current status and growth prospects. Following the discussion of tribal college status, an organizational development model will be used to identify and assess the role that libraries play in the tribal colleges' efforts to meet their institutional objectives.

TRIBAL COLLEGE STATUS

\section{Curriculum}

Tribal colleges parallel most nontribal community colleges in offering two-year degrees in general education and in professional and paraprofessional fields. Two of the colleges in South Dakota (Oglala Lakota and Sinte Gleska) have developed baccalaureate degree programs in education, business administration, and human services. Unique among these tribal colleges, Sinte Gleska also offers a master's degree in education. ${ }^{13}$

\section{Culture}

The role of culture in the curriculum of tribal colleges is important. As previously stated, preservation of the tribal culture is acknowledged as a key institutional goal of the colleges. This goal is significant when contrasted with past federal educational policies which contributed to the eradication of native cultures by promoting forced assimilation at the expense of intrinsic values. In contrast, the policies of tribal colleges reflect the goal of integrating native culture into the curriculum. As a result, native studies programs are an important component of all tribal colleges.

\section{Enrollment}

The economic lifeblood of all community colleges is student enrollment. Community colleges receive funding based on the number of students who enroll, not on the number of students 
who complete programs or who move on to four-year institutions. ${ }^{14}$ Therefore, tribal colleges are especially affected by enrollment figures because the total community from which each one draws is both small and generally dispersed.

In 1989 , there were 4,400 full-time equivalent students enrolled in tribally controlled colleges throughout the United States. While this number is minuscule compared to the number of students enrolled in nontribal community colleges, it is a notable increase from 1981, when only 1,689 students were enrolled. However, enrollment figures must be considered in relation to total reservation population. For example, in 1989 Salish Kootenai College in Montana had 500 students enrolled out of a tribal community of 3,100 , representing 16 percent of the total population. ${ }^{15}$

Two findings of the Carnegie Report in regard to enrollment merit note. The first is that most of a tribal college's enrolled students live on the reservation, and the second is that most of the students are single women (average age 33) with an average of two dependents. These findings validate the linkages that tribal colleges have with their own communities, particularly with single-parent families.

\section{Resources}

The adequacy of classrooms, libraries, laboratories, and other support systems available to students varies across tribal college campuses. While Navajo Community College has focused on the development of dormitories, classrooms, and recreation facilities within a centralized framework, Oglala Lakota, for example, operates as a decentralized college, offering classes throughout the reservation. Fiscal necessity has forced other campuses to take creative approaches to securing space for instructional purposes.

Two important laws partially address the inadequate funding base of tribal colleges. The 1971 Navajo Community College Act (P.L. 89-192) was of major significance in American Indian higher education because it paved the way for the development of other tribally con- trolled colleges. ${ }^{16}$ For example, Navajo Community College was developed by the Navajos themselves, who established the college with monies from various grants. Two years later, Congress provided support through the Navajo Community College Act. Other tribes recognized the achievement of the Navajos and began to pursue the development of their own colleges. These colleges were the outcome of tribal commitment to higher education made feasible by the Tribally Controlled Community College Assistance Act of 1978 (P.L. 95-471). ${ }^{17}$ This act is central to the survival of tribal colleges because the majority depend on it to meet 80 percent or more of their annual operating expenses. $^{18}$ The problem is that while enrollments have increased, the allocated amount of funds has decreased. The Carnegie Report highlighted this issue:

Congress authorized $\$ 4,000$ per student in the original legislation-an authorized level that has since been increased to nearly $\$ 6,000$-but the amount actually released has become only progressively smaller. In 1980 , for example, \$5 million in federal money was distributed under the Tribally Controlled Community College Act, providing about $\$ 3,000$ per student. This year (1989) the appropriation climbed to $\$ 8.5$ million, but the amount generated for each student declined to $\$ 1,900$ ! In effect, tribal colleges are being penalized for their own success. ${ }^{19}$

Tribal colleges have struggled valiantly to provide quality educational programs in less than adequate facilities for adult students living below the poverty line. They have contended with high faculty and administrative turnover in the face of inadequate funding. Despite these difficulties, a spirit of optimism pervades the tribal colleges' determination to meet their institutional objectives.

\section{Library Status}

Unfortunately, there is a paucity of information in the library literature concerning the status and role of libraries in tribal colleges. Yet libraries were specifically mentioned in the second Carnegie Report recommendation, which urged 
that libraries at tribal colleges be significantly improved through federal government appropriations. ${ }^{20}$ Given the lack of descriptive literature and research literature in this area, I conducted interviews with seven tribal college presidents in January 1990 to determine the status of libraries within these institutions. ${ }^{21}$ One of the indicators of library status is the availability of a librarian. Only one of the seven colleges had a full-time librarian with an MLS. Five of the seven colleges had librarians with college or graduate degrees in other fields, and one of the colleges was conducting a search for a librarian.

The range of services, facilities, and adequacy of collections varies among the colleges. Little Big Horn College Library is located in a gymnasium and houses 6,500 volumes. Navajo Community College has a functioning community college library with 45,000 volumes. In the interviews conducted thus far, all seven college presidents recognized that the colleges require additional information resources. Specifically mentioned by the presidents was the desire to enhance access to various databases, increase acquisition and preservation of archival materials, expand reference services to support broader curriculum, and facilitate the delivery of communitybased health and educational programs.

\section{DEVELOPMENTAL MODEL}

Having briefly identified the institutional goals of tribal colleges and their current operational status, I will now apply a model for identifying and assessing the role of libraries and information resources in meeting the colleges' institutional goals and objectives. While there are numerous developmental models with close parallels, I will use the model developed by Eric G. Flamholtz and his associates. ${ }^{22}$ The Flamholtz model has been successfully used to assess the stages of growth in developing organizations.

\section{Organizational Growth}

The Flamholtz model has seen its greatest value in respect to organizations undergoing significant transition and growth. For the purposes of this article, the primary value of the model is that administrators have used it for managing transition in a limited resources environment. The focus of this study is to examine the role of libraries at each stage of tribal college growth. The Flamholtz model defines four stages of growth common to all maturing organizations:

1. The New Venture Stage, which focuses on preparation, planning and analysis;

2. The Expansion Stage, where the emphasis is on increasing resources and enhancing services;

3. The Professionalizing Stage, whereby methods, procedures and practices are formalized; and

4. The Consolidation Stage, where the organization's objectives are both accepted and operationalized throughout the system. ${ }^{23}$

Applying the model to tribal colleges shows that their very existence is a testimony to the new ventures stage of their development. Tribal colleges were a direct result of community activity and were initially founded as culturally unique responses to the tribes' educational requirements. During this initial stage, tribal colleges concentrated on defining the educational population, planning and developing a curriculum, identifying faculty and administration requirements, securing space for facilities, designing support systems, and establishing budget requirements and allocations.

During this initial stage, tribal colleges explicitly considered the core requirements for providing library and information services to support both the curriculum and potential community needs. As previously stated, one of the unique goals of the tribal college was to serve proactively as the institutional guardian of tribal culture and tradition. One specific manifestation of this goal during this first stage was the attention given by some tribal colleges to including archival functions within the library. These functions were linked directly to the desire of the community to have ready access to the print and nonprint 
materials associated with the tribe's history and current status.

During this start-up stage, tribal colleges also recognized the need to identify the level of library and information resources necessary to support the core curriculum. As might be expected, the result was that each individual college determined what constituted the appropriate level of library and information resources for its institution.

The developmental model postulates that during the next stage, expansion, institutions concentrate on acquiring the fiscal, human, and material resources necessary to begin providing the services they have planned for the end-users. For the tribal college, this implementation and growth stage translates to enrolling students, communicating its mission to the community, offering a core curriculum, recruiting and retaining faculty and staff, and preparing for accreditation. At this second stage, the tribal college makes a conscious effort to enhance its economic commitment to the community. One of the more tangible outcomes of this commitment takes the form of college alliance with community health care providers, especially with regard to drug and alcohol abuse and mental health programs. During this stage, the community also becomes increasingly integrated into various components of the college curriculum. In essence, the college seeks ways to expand internally and externally into the community.

The adequacy of library and information resources is an important consideration during the expansion phase. Each tribal college deals daily with the reality that library and information resourcesincluding staff, space, equipment, and materials - are barely adequate to meet the needs of students, faculty, administration, and community. While resource limitations are acute in all areas, they are especially evident in the level of professional staffing and the libraries' use of complementary electronic technology, such as computers. At this stage, library and information resources attempt to play integral roles in meeting at least two of the tribal college's immediate objec- tives: first, basic curriculum support by providing students and faculty with materials, reference services, and basic research support; and second, community support by meeting the basic needs of community-based individuals and agencies, particularly those working in health care and related areas.

Each tribal college deals daily with the reality that library and information resources are barely adequate to meet the needs of students.... and [the] community.

As an institution enhances its ability to deliver products or services, it migrates to the professionalizing stage, which is characterized by the building of the management infrastructure to support the institution's achievement of its objectives. This third stage requires a qualitative change in the nature of the institution, particularly in respect to restructuring and formalizing goals, defining managerial responsibilities, and establishing procedures and control systems. In the professionalizing stage, institutions need to formalize a planned program of organizational development with a dual focus of implementing operational systems and improving the capabilities of the people who manage the institutions. For tribal colleges, this stage is characterized by broadening the curriculum and by improving support for student and faculty research.

At this stage, tribal colleges will have to depend increasingly on the functional capabilities of their libraries because the libraries' resources and services ensure the colleges' ability to support an enhanced curriculum and a research orientation. Most tribal colleges are just now entering this third stage because of their relatively short history. As previously stated, one-half of those tribal colleges now migrating through this stage have an overarching requirement-accreditation-that must be met in order to ensure their ability to provide an officially recognized level of quality education. The 
emphasis on libraries and their related information resources is significant, as libraries are specifically referenced in accreditation handbooks as one of the standards by which accreditation is granted.

During the accreditation process, a library must demonstrate competencies in three areas. The first has to do with the degree to which the philosophy, goals, and objectives of the library reflect the institution's (tribal college's) goals and objectives. The second major area is that of the quality, quantity, and appropriateness of library staff, holdings, services, facilities, and budget. The third area relates to evaluating the use of library services by the college community.

The developmental model used by Flamholtz and other organizational theorists suggests that institutions encounter a different type of challenge in the consolidation stage. During this stage, the institution moves from implementing workable systems for planning, organization, management development, and control to consolidating its more intangible asset: the institutional culture. The development of institutional culture is necessary to complete the institution's transition from a fledgling entity to a professionally managed one.

Some tribal colleges are just now beginning to address how they will manage transition during this fourth stage. The preliminary view held by the seven tribal college presidents contacted for this article is that at least three key goals must be met during this consolidation stage. The first is the tribal college's ability to direct or control its own future by successfully competing for and obtaining external or noncommunity-based monies. The second goal concerns the college's being recognized as a contributing institution by other tribal colleges as well as by the larger educational community. The third goal is to increase the presence of faculty and administration, which reflects the ethnic and cultural composition of the community. ${ }^{24}$

Libraries and information services will have a critical role to play within the tribal colleges as they move toward the consolidation stage. During this stage of tribal college development, the role of the library will be essential to the colleges' achievement of the three aforementioned goals. The library has an especially vital contribution to make in the area of institutional recognition and cooperation. That contribution takes the form of the library's ability to forge cooperative ties with other libraries and information networks, including other tribal college libraries. As a result, the linking of the tribal college's library resources, including the archives, to other institutions is in itself a measure of institutional recognition.

\section{Developmental Tasks}

Tribal colleges exist as a result of a self-determined effort by American Indians to develop culturally sensitive institutions capable of providing a range of relevant educational services. Currently, they are facing the same management issues encountered by other developing organizations as they move through stages of organizational growth. Having presented the four stages of organizational growth according to Flamholtz and applied them to the growth of tribal colleges, I will now consider the interplay between the colleges' developmental tasks and those of the libraries undertaken to achieve the institutional objectives. $^{25}$

The first set of tasks undertaken by the tribal college library is to define its philosophy, establish its goals, and specify its operational procedures in relation to supporting the overall mission and objectives of the tribal college. ${ }^{26}$ Concurrent with this set of tasks is the requirement to plan and provide core library materials and services to assist students and faculty. While it is making basic library services available, the library must frame and implement a plan for increasing staff, expanding holdings, adding services, and improving facilities to better serve students and faculty in addition to the local community.

Following the accomplishment of the first set of tasks, the library's focus turns to the operational systems necessary for the organization and dissemination of 
the library's resources. This includes attention to the following: technical processing of materials, including archival and multimedia resources; consistent provision of reference and basic research services; improved delivery of archival services; circulation control systems for all materials; and evaluative measures of resource use and service quality.

The third set of developmental tasks centers on acquiring and developing the human and physical resources needed to support an adequate level of services. For the tribal college library, the immediate priorities are to professionalize the staff (librarians with an MLS), to enhance the holdings (including archival holdings), and to increase services to the community. The tribal college is similarly engaged in retaining and nurturing faculty, supporting research efforts, improving physical facilities, and actively supporting community-based programs.

The aforementioned tasks, in turn, require the development of those library operational systems needed to implement policies and procedures for expanding the range of library programs. These operational systems address the following functional areas: material accessibility, resource selection guidelines, principles of collection management, guidelines for budget preparation, procedures for staff development, plans for technology implementation, and internal performance measures. The college is similarly involved in implementing operational systems for budget formations, staffing programs, community relationships, and internal assessments.

The Flamholtz model characterizes the fifth set of tasks as developing the management systems required for the overall functioning of the organization on a long-term basis. Comparably, the tribal college's emphasis is directed at strategic, operational, and contingency planning, with the immediate purpose of achieving accreditation and cultural integrity. Concurrently, the tribal college library seeks to implement management systems for determining collection policies, community involvement, staff development, technology implementation, and internal assessments (personnel and information resources).

The successful completion of these five sets of developmental tasks is predicated on the early formalization of tribal college libraries' involvement in the colleges' planning processes. As a result of successfully implementing these tasks, college administrations and library administrations become partners in implementing new academic and community-based programs.

Application of the model has shown that these tasks are always being performed to some degree at any given point in time by virtually all institutions, but that they do not always require the same amount of emphasis at any particular stage. The utility of the model was validated by a representative sample of seven tribal college presidents who agreed unanimously with its application to tribal college development. ${ }^{27}$ The presidents also concurred that these developmental tasks are being performed currently at both the broad institutional level and the departmental (library) level. In addition, they noted that within the tribal college structure, economic considerations affect the movement of any given department from one stage to another.

While most tribal colleges are engaged in the developmental tasks associated with the second (expansion) and third (professionalizing) stages, a few colleges are moving toward stage four (consolidation). One tribal college president, Elgin Bad Wound of Oglala Lakota College, observed that movement within the four stages of development might be more accurately characterized in the tribal setting as circular rather than linear. The remainder of this article identifies that set of variables and hypotheses that will be critical for tribal colleges as they move through the organizational growth stages and achieve their goals and objectives.

\section{HYPOTHESES}

The organizational development model as applied to tribal colleges provides a framework for considering the role of libraries in supporting a range of institu- 
tional objectives. This model makes it possible to identify specifically those developmental tasks that have strong linkages between the institution and the library. While a number of hypotheses can be generated readily through application of the developmental model, this study will focus on the set of hypotheses that contribute to the tribal college's set of unique objectives, specifically those concerned with preserving tribal culture, enhancing community economic opportunity, and improving health care.

The primary objective of this article is to establish a framework for conducting a longitudinal study of the role of libraries in meeting tribal college objectives. Consequently, the hypotheses generated in the succeeding section will be tested in the next phase of the research. Discussion of the hypotheses is limited to providing operational definitions and linking the hypotheses to the institutional goals.

Also, the proposed hypotheses were submitted to the representative sample of tribal college presidents. The consensus among the group was that the hypotheses were relevant, reasonable, and testable. Most of the presidents suggested that low faculty salaries be controlled for as a factor that might affect faculty turnover in the third and fourth hypotheses.

\section{Tribal Culture}

The preservation of tribal culture is a tribal college objective that is most evident in both the curriculum and the projects and programs related to community involvement. Based on the Carnegie Report and the series of personal interviews, a primary criterion used by tribal colleges for assessing their effectiveness in meeting this objective is the extent of community use of institutional resources-especially tribal archives, where available. ${ }^{28}$ The development of a tribal archives under the management of the tribal college library is one of the most visible demonstrations of the college's commitment to the preservation of tribal culture. The question to be addressed here is the extent to which the archival function of libraries contributes to the tribal college's objective of preserving tribal culture.

The primary objective of this article is to establish a framework for conducting a longitudinal study of the role of libraries in meeting tribal college objectives.

"Archives" may be defined as "those records of any public or private institution which are judged worthy of permanent preservation for reference and research purposes and which have been deposited or have been selected for deposit in an archival institution." ${ }^{29}$ This study makes no distinction between the definition of an archives in a tribal setting and an archives in a nontribal setting. John Flekner, one of the recognized experts in this field, supports this position when he defines a tribal archives as "a body of materials permanently retained because it contains historically valuable information for the tribe and tribal members." ${ }^{\prime 30}$

The following hypothesis considers the role of an archives in respect to meeting the institution's objective of preserving tribal culture: Tribal college libraries that have an archives have more community use than those tribal college libraries without archives. The measure of "community use" to be applied in this study will draw from the performance measures identified by Nancy Van House and her colleagues in Output Measures for Public Libraries. These measures may include library visits per capita, library registrations, circulation per capita, inlibrary materials use per capita, and turnover rate. ${ }^{31}$ "Community" will refer to two groupings that must be distinguished: (1) the students, faculty, and administration of the college and (2) the area residents who are not students, faculty, or administrators of the college.

\section{Economic Enhancement of Community}

The role of the library in contributing to the tribal colleges' objective of enhancing community-based economic oppor- 
tunity was presented in the discussion of the developmental model with its parallels between the college and the library's tasks, specifically in the third set of tasks. What contribution, if any, can the library make to enable the community to enhance its economic base? A second hypothesis considers this question: Funding proposals submitted by tribal organizations that use tribal college library resources in proposal preparation are more frequently granted than those proposals submitted by tribal organizations that do not use tribal college library resources.

Before we consider this hypothesis, three terms require definition: (1) "funding proposal" is identified as a written document submitted to a funding agency (nontribal, nonlocal) for purposes of obtaining monies to support community-based programs or services; (2) "tribal organization" refers to any formalized group, department, agency, or program recognized by the current tribal government; and (3) "tribal college library resources" include the complete holdings and services of the tribal college library, including print, nonprint, archives, reference, and research. Testing this hypothesis will require control for the use of nontribal college library (e.g., public or special library) resources.

\section{Health Care Support}

The third unique tribal college objective is that of addressing the provision of health care programs within the community, specifically in the areas of alcohol and drug abuse. Tribal colleges have attempted to address this issue by emphasizing three approaches: the training of health care professionals, the provision of physical facilities to support health care programs, and the direct implementation of community health education efforts. Two of the major obstacles faced by tribal colleges in effectively supporting their total curriculum, especially the health sciences curriculum, have been the high turnover rate of faculty and the limited access to the library information resources needed to support the health sciences curriculum.

As the primary information resource within the institution, the library has a critical role to play in retaining faculty and in increasing access to specialized information resources. The hypothesis to be tested in this area is that tribal colleges that have established library networking and cooperative relationships with other libraries and information service providers experience less faculty turnover than tribal colleges that do not have such relationships. It may be possible to test a more specific hypothesis: Tribal colleges that have library networking and cooperative relationships with health services information providers experience less health science faculty turnover than tribal colleges that do not.

Three terms require definition in respect to testing this set of hypotheses. "Established library networking relationship" refers to a contractual agreement that has been in place for a minimum of one year whereby the tribal college library has access, via electronic or nonelectronic means, to information from information service providers such as Medlars, OCLC, and DIALOG.

"Established library cooperative relationship" refers to a contractual agreement that has been in place for a minimum of one year between the tribal college library and any other libraries (public, special, or academic) to share print and nonprint resources. Interlibrary loan arrangements are an example of this type of cooperative relationship.

"Faculty turnover" is more difficult to define because of the relatively short history of the tribal college. According to Arthur Cohen, a leading scholar in the field, turnover in nontribal American community colleges for full-time faculty is typically measured in reference to a mean institutional affiliation of twelve years..$^{32}$ For the purpose of testing this hypothesis, "faculty turnover" will be represented as the annualized percentage of vacancies over a five-year period caused by the voluntary departure (excluding death and retirement) of faculty members.

\section{Accreditation}

Apart from these three objectives, which are specific to tribal colleges, the 
colleges also strive to meet the five previously cited objectives that are common to all community colleges: (1) preparation for transfer; (2) preparation for job entry; (3) literacy development; (4) career upgrading; and (5) provision of personal interest activities. The tribal colleges' ability to meet these five objectives is related to their success in achieving and maintaining accreditation. The final hypothesis to be presented considers the role of the tribal college library in helping to achieve institutional accreditation.

According to the Accreditation Handbook, "the purposes of a library and learning resources program is to support and improve instruction and learning in ways consistent with the philosophy and evolving curricular programs of the institution." ${ }^{\prime 3}$ Therefore, those tribal colleges that, from their founding, have identified and implemented appropriate library services to support all their institutional objectives should be more successful in achieving accreditation, particularly at the initial time of submission. Based on this rationale, the final hypothesis is: Tribal colleges with written strategic plans explicitly identifying the role of the library in meeting their institutional objectives achieve accreditation on their initial review more frequently than tribal colleges that do not have such plans. In this hypothesis, "written strategic plan" is defined as an officially approved tribal college document that addresses the educational mission, philosophy, goals, and objectives of the institution.

These four hypotheses focus on the role of the library in meeting the tribal college's objectives, particularly that set related to tribal culture, economic empowerment, and health care. While other hypotheses relate more directly to internal assessments of library performance, the intent in this article has been to derive, from the development model, hypotheses that can validate the role libraries have in meeting the institutional objectives of the tribal colleges.

\section{CONCLUSION}

While tribal college presidents recognize the value of libraries, a quantum leap in the provision of information services is needed to help meet their institutional objectives. For example, few tribal colleges possess adeqquatecomputer technology, yet in order to meet institutional objectives an electronic networking approach is essential. Similarly, the strong focus on archival collections for preserving tribal culture and history suggests the appropriateness of using newer technology such as image processing and CD-ROM.

The role of libraries in tribal college development provides the field of academic librarianship with a unique opportunity to recast the mission of libraries with respect to meeting institutional and community-based objectives. The nature of the tribal college has many parallels to the entrepreneurial nature of many businesses. As such, the academic library world may want to look at the applicability of developmental models that have been used in the business community. The dearth of research in this area mandates an intensive look at the role of tribal college libraries in a nonbiased fashion, free of preconceived notions.

\section{REFERENCES AND NOTES}

1. The first such treaty was signed between the United States and the Delaware Tribe on September 17, 1778. From that date until 1871, treaties were the legal basis of federal policies concerning American Indian education. Thomas Thompson, ed., The Schooling of Native America (Washington, D.C.: American Assn. of Colleges for Teacher Education, 1978), p.168.

2. Ibid., p.169.

3. Margaret Comell Szasz and Carmelita Ryan, "American Indian Education," in History of IndianWhite Relations .ed., Wilcombe Wasburn, v.4. (Washington, D.C.: Smithsonian, 1988), p.289.

4. Thompson, The Schooling of Native America, p.170. 
5. Steven Crum, "The Idea of an Indian College or University in Twentieth-Century America before the Formation of the Navajo Community College in 1968," Tribal College 1:20-21 (Summer 1989).

6. For a list of tribally controlled colleges, send a stamped, self-addressed envelope to the author.

7. Arthur Cohen, "The Transfer Indicator," unpublished paper presented at the American Association of Community and Junior Colleges annual convention, Seattle, April 24, 1990 (University of California-Los Angeles and Center for the Study of Community Colleges, 1990), p.1.

8. Carnegie Foundation for the Advancement of Teaching, Tribal Colleges: Shaping the Future of Native America (Princeton, N.J.: Carnegie Fndn. for the Advancement of Teaching, 1989), p.41, 45-46.

9. Norman Oppelt, "The Tribally Controlled Colleges in the 1980s: Higher Education's Best Kept Secret," American Indian Culture and Research Journal 8:39 (1984).

10. Northwest Association of Schools and Colleges, Accreditation Handbook (Seattle, Wash.: Northwest Assn. of Schools and Colleges, 1988), p.3.

11. Carnegie Foundation, Tribal Colleges, p.27.

12. Carolyn J. Mooney, "Colleges for American Indians Said to Need Money and Recognition," Chronicle of Higher Education, v.36, 11:A20 (Nov. 15, 1989).

13. Carnegie Foundation, Tribal Colleges, p.28.

14. Cohen, "The Transfer Indicator," p.2.

15. Carnegie Foundation, Tribal Colleges, p. 30.

16. U.S. Congress, House (1971), P.L. 89-192 Navajo Community College Assistance Act, 89th Congress, 1st Session.

17. U.S. Congress, House (1978), P.L. 95-471 Tribally Controlled Community College Assistance Act of 1978, 95th Congress, 2d Session.

18. Presently, it is not possible to obtain specific data related to operating expense budgets for individual colleges. This is due largely to complex bureaucratic regulations and the fragmented nature of funding sources that contribute to operating budgets.

19. Carnegie Foundation, Tribal Colleges, p.36-37.

20. Ibid., p.72.

21. Personal interviews conducted between Cheryl Duran and the presidents of the seven colleges which were included in the Carnegie Special Report, Tribal Colleges: Shaping the Future of Native America (Interviews conducted January 17-22, 1990). A formal interview schedule was administered; there was a $100 \%$ response rate.

22. Eric G. Flamholtz, How to Make the Transition from an Entrepreneurship to a Professionally Managed Firm (San Francisco: Jossey-Bass, 1986), p.31-47.

23. Ibid., p.32-33.

24. Cheryl Duran, personal interviews with seven tribal college presidents, January 1990.

25. For a copy of the developmental task sets chart, which presents a three-tiered analysis of the developmental tasks associated with nontribal organizations, the tribal college, and the tribal college library, send a stamped, self-addressed envelope to the author.

26. These library tasks are derived from the Accreditation Handbook, p.45-46.

27. Second set of personal interviews conducted between Cheryl Duran and the presidents of seven colleges which were included in the Carnegie Special Report, Tribal Colleges: Shaping the Future of Native America (Interviews conducted July 16-20, 1990).

28. Cheryl Duran, personal interviews with seven tribal college presidents, January 1990.

29. T. R. Schellenberg, Modern Archives: Principles and Techniques (Chicago: Univ. of Chicago Pr., 1956), p.16.

30. John Fleckner, Native American Archives: An Introduction (Chicago: Soc. of American Archivists, 1984), p.1.

31. Nancy A. Van House and others, Output Measures for Public Libraries: A Manual of Standardized Procedures, 2d ed. (Chicago: American Library Assn., 1987), p.37-49.

32. Personal interview between Duran and Cohen, May 22, 1990, University of CaliforniaLos Angeles.

33. Northwest Association, Accreditation Handbook, p.44. 


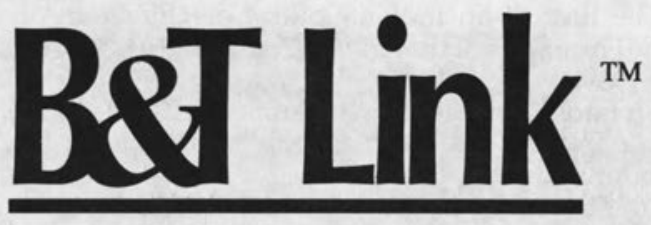

\section{It's now even bigger, faster, and more accurate - connecting you to our 10 million book inventory plus any in-print, out-of-print, and forthcoming title.}

Fill all your book ordering needs in one place in record time thanks to B\&T Link ${ }^{\mathrm{TM}}$ - an extraordinary system of search and order software modules from Baker \& Taylor Books. With more refinements and conveniences than you ever dreamed possible, B\&T Link literally puts any book at your fingertips.

\section{Module 1: Ordering}

Get it smarter, faster, easier. No matter how simple or intricate your ordering method, ordering through B\&T Link gives you lots of new advantages. Our special order feature lets you customize every line item with customer requests, multiple distribution notes, as well as print notification postcards.

Now, in addition to sending orders upon completion, you

can also transmit

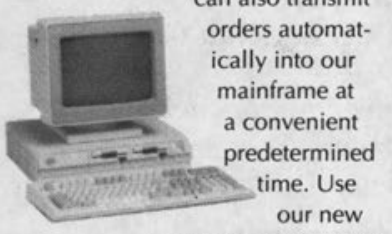

ordering interfaces to output data in a variety of standard formats to other software products. Or check in shipments with our new on-screen receiving.

And of course, B\&T Link still provides the most comprehensive confirmation report you can get. And it's yours free.

\section{Module 2: Database, The Title Source}

Find any book, in every detail. B\&T Link's new Module 2 bibliographic software on CD-Rom puts you in complete command of over 1.2 million book, video, audio, calendar, in-print, out-of-print and forthcoming titles. You'll enjoy extraordinary accuracy through our system of "linked" ISBN's that automatically takes you to the most recent ISBN. Nine easy ways to search our comprehensive database allow you to quickly create a title listing, including hard-to-find titles. We've even made searching up to $20 \%$ faster.
Database, The Title Source reports on everything from multiple bindings to the latest price and publication status, and is updated every month to include more than 80,000 changes.

\section{Module 3: Inventory}

Take stock at a glance. Using B\&T Link Inventory software is like standing in our warehouse. You'll know immediately what's in stock and what's on order in your regional service center.

You'll get weekly updates on diskettes of an inventory with over 120,000 titles. And that's not all. Soon to be added to the B\&T Link system are Invoicing, Ordering History, Fund Accounting, and Open-to-Buy modules. When it comes to getting a book, B\&T Link is the system that does it with convenience and the any book advantage.

For more information, call

800-233-3657

\section{BAKER \& TAYLOR Books}




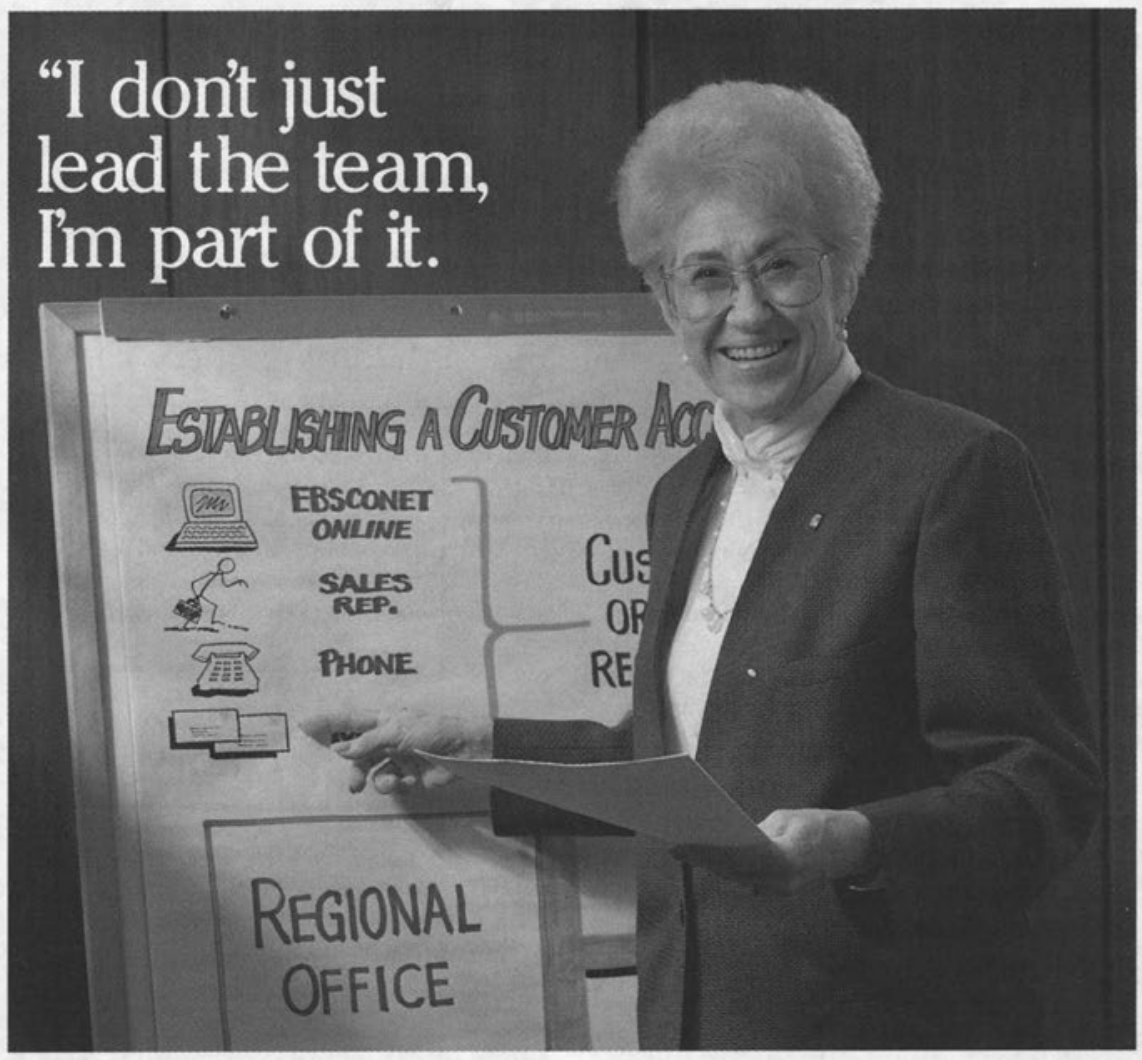

"Teamwork is a primary reason EBSCO has successfully served the serials management needs of librarians for so many years. Our concept of providing subscription service is based on teams of dedicated employees serving customers in specific regions. My staff and I serve libraries in the Mountain/Plains States while eight other U.S. teams handle the serials needs of customers from Maine to Alaska to the Virgin Islands. And there are 17 more EBSCO offices located throughout the world, all fully staffed with a work force of serials professionals committed to working toward one goal.

"Maintaining a team effort is a lot of work. It requires constant communication, cooperation and corrective action from everyone.
We stress that every job and every detail, no matter how small, is important to the superior service our customers have come to expect. And we take nothing for granted."

Juanita O'Neall Vice President/General Manager Denver, CO Regional Office

At EBSCO, we think librarians deserve to be served by a service-oriented subscription agency. Don't you?

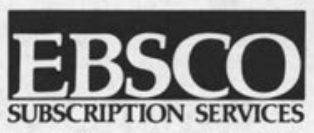

International Headquarters

P.O. Box 1943

Birmingham, AL 35201 (205) $991-6600$ 